ACCEPTED MANUSCRIPT

\title{
Coherent averaging of pseudorandom binary stimuli: is the dynamic cerebral autoregulatory response symmetrical?
}

To cite this article before publication: Emmanuel Katsogridakis et al 2017 Physiol. Meas. in press https://doi.org/10.1088/1361-6579/aa9086

\section{Manuscript version: Accepted Manuscript}

Accepted Manuscript is "the version of the article accepted for publication including all changes made as a result of the peer review process, and which may also include the addition to the article by IOP Publishing of a header, an article ID, a cover sheet and/or an 'Accepted

Manuscript' watermark, but excluding any other editing, typesetting or other changes made by IOP Publishing and/or its licensors"

This Accepted Manuscript is @ 2017 Institute of Physics and Engineering in Medicine.

During the embargo period (the 12 month period from the publication of the Version of Record of this article), the Accepted Manuscript is fully protected by copyright and cannot be reused or reposted elsewhere.

As the Version of Record of this article is going to be / has been published on a subscription basis, this Accepted Manuscript is available for reuse under a CC BY-NC-ND 3.0 licence after the 12 month embargo period.

After the embargo period, everyone is permitted to use copy and redistribute this article for non-commercial purposes only, provided that they adhere to all the terms of the licence https://creativecommons.org/licences/by-nc-nd/3.0

Although reasonable endeavours have been taken to obtain all necessary permissions from third parties to include their copyrighted content within this article, their full citation and copyright line may not be present in this Accepted Manuscript version. Before using any content from this article, please refer to the Version of Record on IOPscience once published for full citation and copyright details, as permissions will likely be required. All third party content is fully copyright protected, unless specifically stated otherwise in the figure caption in the Version of Record.

View the article online for updates and enhancements. 
Coherent averaging of pseudorandom binary stimuli: is the dynamic cerebral autoregulatory response symmetrical?

Emmanuel Katsogridakis ${ }^{1}$, David M. Simpson ${ }^{4}$, Glen Bush ${ }^{2}$, Lingke Fan ${ }^{2}$, Anthony A. Birch ${ }^{3}$, Robert Allen ${ }^{4}$, John F. Potter ${ }^{5}$, Ronney B. Panerai ${ }^{1,6}$

${ }^{1}$ Department of Cardiovascular Sciences, University of Leicester, United Kingdom.

${ }^{2}$ Department of Medical Physics, Leicester Royal Infirmary, University Hospitals of Leicester NHS Trust, Leicester, United Kingdom

${ }^{3}$ Neurological Physics Group, Department of Medical Physics and Bioengineering, University Hospital Southampton NHS Foundation Trust, Southampton, United Kingdom

${ }^{4}$ Institute of Sound and Vibration Research, University of Southampton, United Kingdom

${ }^{5}$ School of Medicine, Health Policy and Practice, University of East Anglia, Norwich, United Kingdom

${ }^{6}$ Leicester NIHR Biomedical Research Unit in Cardiovascular Sciences, Glenfield Hospital, Leicester, United Kingdom

Abbreviated title: The symmetry of the autoregulatory response.

\section{Corresponding author:}

Ronney B. Panerai

Department of Cardiovascular Sciences

Level 1, Sandringham Building Leicester Royal Infirmary, LE15WW

Leicester, UK

E-mail: rp9@le.ac.uk

Tel: +44(0)1162585511

Fax: +44(0)1162586070 


\section{ABSTRACT}

Objective: Previous studies on cerebral autoregulation have shown the existence of hemispheric symmetry, which may be altered in stroke and traumatic brain injury. There is a paucity of data however on whether the response is symmetrical between those disturbances that cause cerebral hyperperfusion, to those that cause hypoperfusion. Our aim was to investigate whether the responses of cerebral autoregulation to haemodynamic stimuli of different directions are symmetrical.

Approach: Using a previously described assessment method, we employed coherent averaging of the cerebral blood flow velocity (CBFV) responses to thigh cuff inflation and deflation, as driven by pseudorandom binary sequences, whilst simultaneously altering the inspired $\mathrm{CO}_{2}$. The symmetry of the autoregulatory response was assessed with regards to two parameters, its speed and gain. Using the first harmonic method, critical closing pressure $(\mathrm{CrCP})$ and resistance area product (RAP) were estimated, and the gain of the autoregulatory response was calculated by performing linear regression between the coherent averages of arterial blood pressure (ABP) and $\mathrm{CBFV}, \mathrm{ABP}$ and $\mathrm{CrCP}$ and finally $\mathrm{ABP}$ and RAP. A twoway repeated measures ANOVA was used to assess for the effect of the direction of change in $\mathrm{ABP}$ and the method of $\mathrm{CO}_{2}$ administration.

Main results: Our results suggest that whilst the direction of ABP change does not have a significant effect, the effect of $\mathrm{CO}_{2}$ administration method is highly significant $\quad\left(\mathrm{p}<10^{-4}\right)$.

Significance: This is the first report to report to demonstrate the symmetry of the autoregulatory response to stimuli of different directions as well as the short term dynamics of RAP and CrCP under intermittent and constant hypercapnia. As haemodynamic stimulus direction does not appear to have an influence, our findings validate previous work done using different assessment methods. 


\section{INTRODUCTION}

Cerebral autoregulation $(C A)$ is the complex homeostatic mechanism through which the cerebrovascular bed maintains control over regional blood flow (Lassen, 1959).

Assessment of its functional status has become a topic of interest as it was demonstrated that dynamic cerebral autoregulation $(d C A)$ may be impaired in stroke, carotid stenosis and traumatic brain injury(Brady et al., 2009, Dagal and Lam, 2009, Greene, 2010, Guendling et al., 2006, Joshi et al., 2010, Lang et al., 2003, Rasulo et al., 2008, Sharma et al., 2010). Two main ensembles of methods have been proposed for the assessment of the functional status of dynamic CA.

The first set of assessment methods relies on the induction of a haemodynamic stimulus that will elicit an autoregulatory response (Aaslid et al., 1989, Birch et al., 2002, Blaber et al., 1997, Dawson et al., 1999, Diehl et al., 1995, Reinhard et al., 2000). The second ensemble capitalizes on the spontaneous variability of arterial blood pressure $(A B P)$ and cerebral blood flow velocity $(C B F V)$ in the setting of spontaneous fluctuations of $\mathrm{ABP}$ as well as from ectopic heart beats (Eames et al., 2005, Panerai et al., 1995, Panerai et al., 1998, Zhang et al., 1998).

We have recently proposed a new method for the integrated assessment of cerebral haemodynamics that relies on the use of pseudorandom binary sequences to drive the inflation of thigh cuffs and the administration of $\mathrm{CO}_{2}$ (Katsogridakis et al., 2012). The method was shown to be capable of augmenting ABP and CBFV variability without distorting dCA estimates through causing sympathetic excitation (Katsogridakis et al., 2013). 
In this paper we use the intermittent nature of the stimuli used in our assessment method to explore the symmetry of the autoregulatory response, using coherent averaging.

\section{METHODS}

Hardware and software. For the purposes of this study, a modification of the thigh cuff method was used, combined with the intermittent and constant administration of $\mathrm{CO}_{2}$, at a concentration of $5 \%$. The operating principles and controlling software of the device used to achieve this have been described in greater detail in previous communications (Fan et al., 2013, Katsogridakis et al., 2012).

Volunteers and experimental set-up. Volunteers were recruited if their medical history was free of known cardiovascular and neurological disorders. Upon their arrival, volunteers were reminded of the protocol, the instrumentation was demonstrated, its function explained and written informed consent was obtained. The study was approved by the Nottingham Research Ethics Committee, United Kingdom.

The participants were asked to assume a súpine position on the experimental couch. Following a brief settling down period, brachial ABP was measured by means of automatic sphygmomanometry and the thigh cuffs and face mask were attached. A trial inflation / deflation cycle was performed to familiarize participants with the procedure and to ensure the uninterrupted flow of air to the cuffs.

Arterial blood pressure was monitored noninvasively using the arterial volume clamp method (Finometer, Ohmeda). Transcranial Doppler (Companion III, Viasys Healthcare) identification of both middle cerebral arteries $(M C A)$ was performed using two $2 \mathrm{MHz}$ probes, held in place with a custom built headframe. The mask was connected to the $\mathrm{CO}_{2}$ delivery 
system and the capnograph (Datex, Normocap 200) to measure end-tidal $\mathrm{CO}_{2}\left(\mathrm{EtCO}_{2}\right)$ levels. A three-lead surface electrocardiogram $(E C G)$ was also recorded.

Following a brief period of supine rest which was required for the setup and connection of all monitoring devices the participants underwent a five minute baseline recording. Three additional manoeuvres were then performed for every volunteer and were administered in random order. These manoeuvres corresponded to the random inflation/deflation of thigh cuffs under normocapnic, constant hypercapnic and intermittent/pseudorandom hypercapnic conditions. For the two manoeuvres where thigh cuff inflation was combined with $\mathrm{CO}_{2}$ administration (the constant hypercapnic and intermittent/pseudorandom administration), this was administered at a concentration of $5 \%$ in air through the face mask.

Data recording and pre-processing. All signals were sampled at a rate of $500 \mathrm{~Hz}$ and recorded in real time on a dedicated personal computer. Offline, signals were visually inspected, spikes and artifacts were removed and the ABP signal was calibrated. The recorded signals were then filtered with an eighth order Butterworth low-pass filter with a cut-off frequency of $20 \mathrm{~Hz}$, applied in a forward and reverse direction to avoid time-shift.

The beginning and end of each cardiac cycle were detected from the ECG signal, to estimate heart rate $(H R)$ and mean beat-to-beat values were calculated for the recorded signals. For each cardiac cycle, the instantaneous relationship between $\mathrm{CBFV}$ and $\mathrm{ABP}$ was used to estimate the critical closing pressure $(C r C P)$ and resistance-area product $(R A P)$ of the cerebral circulation using the first harmonic method. Estimates were then interpolated using a third order polynomial and resampled at $5 \mathrm{~Hz}$ to create time series with a uniform time base.

The resistance area product was estimated for each cardiac cycle from the raw data, using the first harmonic of the $\operatorname{ABP}\left(A_{l}\right)$ and $\operatorname{CBFV}\left(V_{l}\right)$ signals (Michel et al., 1997) as: 


$$
R A P=\frac{A_{1}}{V_{1}}
$$

Having estimated RAP, the critical closing pressure (CrCP) was then calculated from the relationship:

$$
\operatorname{CrCP}=A B P_{m}-R A P \cdot C B F V_{m}
$$

where $A B P_{m}$ and $C B F V_{m}$ are the mean values of $\mathrm{ABP}$ and $\mathrm{CBFV}$ for that particular cardiac cycle.

The mean value of every signal was subtracted.

Coherent averaging. The recorded thigh cuff pressure transducer signal (TCPT) was used to identify the thigh cuff inflation and deflation points, needed for the subsequent coherent averaging analysis. In summary, a peak detection algorithm was used on the numerical derivative of the TCPT signal to identify the thigh cuff inflation time points. A similar approach was used to identify the thigh cuff deflation time points.

Once the thigh cuff inflation and deflation time points were identified, these were used to ensure the alignment of the ABP, CBFV, $\mathrm{CrCP}$ and RAP signals for the subsequent analyses by using a $10 \mathrm{~s}$ segment of data. This consisted of $5 \mathrm{~s}$ length of data preceeding the inflation/deflation event and 5 s data segment following it. These 10s long data segments were then averaged for that recording. Left and right sided estimates were also averaged.

Assessment of the symmetry. The symmetry of the autoregulatory response was assessed with respect to its two components: the gain and speed of the transient response as described in a recent report (Aaslid et al., 2007). In their work Aaslid et al (2007) reviewed the time series and manually selected the time points to be included in the analysis, an approach that introduces bias. To overcome this, we used the whole coherent averaging time series to 


\section{RESULTS}

Statistics. The Shapiro-Wilk test was used to test for normality. All non-normally distributed data were log-transformed. A two-way repeated measures ANOVA was performed to test for differences in the linear regression slope estimates obtained from the inflation and those obtained from the deflation of the thigh cuffs, for different $\mathrm{EtCO}_{2}$ levels. Values of $\mathrm{p}<0.05$ were considered to represent statistical significance.

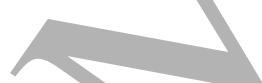

Population estimates for the $\mathrm{ABP}$ and $\mathrm{CBFV}$ coherent averages are presented in Figure 1, whilst for $\mathrm{CrCP}$ and RAP in Figure 2. Coherent averages of $\mathrm{ABP}$ appear to remain largely unaffected by changes in $\mathrm{EtCO}_{2}$ levels for both thigh cuff inflation and deflation (Figure 1, subplots A and B). Similar results were observed with the CBFV coherent averages, where the effect of $\mathrm{CO}_{2}$ in dampening the response to both thigh cuff inflation and release was not apparent (Figure 1, subplots C and D).

Population estimates for the CBFV responses to thigh cuff inflation and release (inverted CBFV) are presented in Figure 3 for normocapnic, intermittent and constant hypercapnic conditions. Though a small difference is observed in the magnitude of the CBFV transient 
response in the form of an overshoot in subplots $\mathrm{A}$ and $\mathrm{B}$, the speed of the response appears to be relatively similar.

The group averaged values for the slope of the regression line between $\mathrm{ABP}$ and $\mathrm{CBFV}, \mathrm{ABP}$ and $\mathrm{CrCP}$ and $\mathrm{ABP}$ and RAP are presented in Table 1. Slope estimates for all parameters (CBFV, $\mathrm{CrCP}$ and $\mathrm{RAP}$ ) were not affected by the direction of changes in blood pressure, however the effect of $\mathrm{CO}_{2}$ was statistically significant ( $\mathrm{p}$ - values are presented in Table 1).

\section{DISCUSSION}

This study confirms our earlier reports with respect to the effectiveness of the new method in amplifying $\mathrm{ABP}$ and $\mathrm{CBFV}$ variability to facilitate the comprehensive assessment of cerebral haemodynamics (Katsogridakis et al., 2013, Katsogridakis et al., 2012). It also demonstrates the usefulness of coherent averaging in extending our understanding of the dynamics of dCA, as it provides new insights about the symmetry of the autoregulatory response and the effect of varying $\mathrm{EtCO}_{2}$ levels on the cerebrovascular bed (Katsogridakis et al., 2016).

A significant effect of the random and/constant administration of $\mathrm{CO}_{2}$ on the transient response of CBFV was not clearly seen (see Figure 1), despite the well understood effects of hypercapnia on dCA (Garnham et al., 1999, Panerai et al., 1999). The reasons for this are not immediately clear, however we hypothesize that this may be related to two reasons: on one hand a short segment of data ( 5 s preceeding and 5 s ensuing the thigh cuff release) was used for the coherent averaging, to ensure no overlap of responses following sequences of different durations occurred, an event that would render physiological interpretation rather difficult. This window of data however may have not been long enough to observe the effects of hypercapnia on CBFV. The second possibility, which we address in the following 
paragraphs, was that the intermittent / pseudorandom administration of $\mathrm{CO}_{2}$ may have not resulted in a physiological effect of a magnitude such that it would be manifest in changes in velocity. As will become apparent in the following paragraphs, the effects of the intermittent $\mathrm{CO}_{2}$ administration were evident in the RAP and $\mathrm{CrCP}$ responses, and were dose-dependent, findings that militate against the likelihood that pseudorandom administration of $\mathrm{CO}_{2}$ has no physiological effect.

As already mentioned, the intermittent administration resulted in a partial impairment of the autoregulatory response which is by the effect $\mathrm{EtCO}_{2}$ levels had on the response of the attributes of the cerebrovascular bed (RAP and $\mathrm{CrCP}$ ) as seen in figure 2 .

The RAP is an index used to represent the relationship between ABP and flow velocity(Evans et al., 1988). Its involvement in the regulation of CBF was récently demonstrated and it is believed to be achieved through myogenic actuators (Panerai et al., 2005). Critical closing pressure on the other hand, has been shown to be representative of the cerebrovascular tone and the influences of ICP (Panerai, 2003), and correlates strongly with $\mathrm{EtCO}_{2}$ levels (Garnham et al., 1999, Panerai, 2003, Panerai et al., 1999, Reinhard et al., 2000, Weyland et al., 2000).

We decided to use both CrCP and RAP to investigate the effect of different methods of administering $\mathrm{CO}_{2}$ on the tone and resistance of the cerebrovascular bed using coherent averaging. Our findings suggest that the method of $\mathrm{CO}_{2}$ administration had a dose dependent effect on both the CrCP and RAP, for both directions of changes in ABP. In particular, hypercapnia appears to prolong the duration and decrease the amplitude of the response of both covariates. 
To the best of our knowledge, this is the first time that a partial impairment of dCA, secondary to the intermittent administration of $\mathrm{CO}_{2}$, has been demonstrated, as seen by its effects on the tone and resistance of the cerebrovascular bed.

The use of coherent averaging also revealed that of the two parameters, CrCP appears to be reacting much faster, for both directions of $\mathrm{ABP}$ transients, with a very sharp transition, whilst the response of RAP appears to be slower and more gradual. This would suggest that $\mathrm{dCA}$ first acts by adjusting the tone of the cerebral arterioles as a crude means of compensating for the CBFV transient, and then modulates resistance for a finer adjustment of the resting levels of CBFV. This finding may have significant implications for the assessment of dCA as it suggests that CrCP may be used to assess dCA in its own right (Dewey et al., 1974).

To investigate the symmetry of autoregulatory response, we decided to use linear regression. The use of the term symmetry warrants further clarification at this point, as it has been employed in the literature to denote different things by different authors. Typically, symmetry is used in the literature in the context of investigations of hemispheric differences in dCA (Schmidt et al., 2003b).

Using conventional metrics of $\mathrm{dCA}$, it was found that no side to side differences exist in healthy adult volunteers at rest (Schmidt et al., 2003b), with differences observed following brain activation (Panerai et al., 2005), traumatic brain injury in adults (Lang et al., 2003, Schmidt et al., 2002, Schmidt et al., 2003a) and paediatric patients (Vavilala et al., 2008). In a recent report however, Aaslid et al. defined symmetry as the absence of marked differences in the speed and gain of the CBFV transient response to cyclical stimuli of different directions (Aaslid et al., 2007) and found strongly asymmetric responses in a population of neurosurgical patients, whilst no significant asymmetries were seen in the control group. A 
critical appraisal of that report would suggest however, that the study may not have been optimally set up to answer the question of asymmetries.

The authors defined asymmetry as any discrepancy in the gain or the speed of the autoregulatory response. Speed however, was not investigated in their report. It is therefore unknown if any discrepancies exist, that would be indicative of asymmetries even in a healthy population. The metric that the authors used, termed in their study' the autoregulatory gain' was defined as the ratio between the difference in critical closing pressure to the difference in arterial blood pressure. No information is provided however on the selection of the points used to calculate the differences, and it is thus unknown if bias has been introduced in the analysis through the subjective selection of points. The observation of strongly asymmetric responses in the neurosurgical population is more compatible with it being the derivative of the traumatic brain injury itself rather than it being reflective of an inherent physiological mechanism. The authors fail to make a distinction and to explain why no asymmetries were observed in the control group. Lastly, the authors do not address the possibility of the discrepancy between the control and patient groups being due to the difference in $\mathrm{EtCO}_{2}$ levels due to the need for the neurosurgical patients to be kept at a state of moderate hypocapnia.

To address some of the aforementioned limitations we performed linear regression analysis between ABP and CrCP. Our finding of a symmetrical dCA response under normocapnic and random hypercapnic conditions is in agreement with their report of an absence of significant asymmetries in the autoregulatory gain observed in healthy volunteers. This is further supported by the similarity in the speed of the CBFV responses to transient changes of $\mathrm{ABP}$ in different direction and by the absence of significant differences in the slopes of the linear regression. 
Constant hypercapnia was then used to simulate a state of impaired autoregulation. Though no difference was observed in the slope of the linear regression, a potential difference in the speed and magnitude of the CBFV transient could be considered indicative of an asymmetry of the autoregulatory response under constant hypercapnia (see Figure 3). This finding is in agreement with the secondary finding of the aforementioned study with respect to the existence of strong asymmetries observed in volunteers with impaired autoregulation.

Study limitations. Measurements of CBFV can reflect changes in CBF as long as the diameter of the insonated vessel remains constant. Several studies have demonstrated that the crosssectional area of the MCA changes minimally (Newell et al., 1994, Serrador et al., 2000) which supports the use of CBFV as a surrogate of CBF.

Due to the sensitivity of $\mathrm{CrCP}$ and RAP to ABP measurement inaccuracies (Panerai et al., 2006) and to the method that was employed for their estimation, comparison of results should be done with caution. For the purposes of this study, we used ABP estimates measured with a different device (Finometer) to that used in the study of Aaslid et al. (2007). The influence that the different ABP measurement methods used may have on estimates of $\mathrm{CrCP}$, and therefore on those of the autoregulatory gain is not known. However, both devices have a similar operating principle, and therefore differences would be expected to be minimal.

Lastly, we performed linear regression between $\mathrm{ABP}$ and $\mathrm{CrCP}$ as an estimate of gain with respect to the tone and resistance of the cerebrovascular bed. Linear regression however, operates under the assumption that measurement errors exist only on the independent variable. As CrCP and RAP are estimated using ABP, irrespective of the estimation method, this assumption is not entirely true. 


\section{CONCLUSIONS}

We have demonstrated that our new assessment protocol can be combined effectively with analytical methods such as coherent averaging to obtain new insights into cerebral haemodynamics. The autoregulatory response, under normocapnic conditions, was found to be symmetrical to stimuli of different directions. dCA appears to act by first adjusting the tone and then the resistance of the cerebral arterioles. More investigations are required to verify our results.

\section{ACKNOWLEDGEMENT}

This study was supported by the UK EPSRC grant nos EP/G008787/1 and EP/G010420/1 


\section{REFERENCES}

AASLID, R., BLAHA, M., SVIRI, G., DOUVILLE, C. M. \& NEWELL, D. W. 2007. Asymmetric dynamic cerebral autoregulatory response to cyclic stimuli. Stroke, 38, 1465-9.

AASLID, R., LINDEGAARD, K. F., SORTEBERG, W. \& NORNES, H. 1989. Cerebral autoregulation dynamics in humans. Stroke, 20, 45-52.

BIRCH, A. A., NEIL-DWYER, G. \& MURRILLS, A. J. 2002. The repeatability of cerebral autoregulation assessment using sinusoidal lower body negative pressure. Physiol Meas, 23, 73-83.

BLABER, A. P., BONDAR, R. L., STEIN, F., DUNPHY, P. T., MORADSHAHI, P., KASSAM, M. S. \& FREEMAN, R. 1997. Transfer function analysis of cerebral autoregulation dynamics in autonomic failure patients. Stroke, 28, 1686-92.

BRADY, K. M., SHAFFNER, D. H., LEE, J. K., EASLEY, R. B., SMIELEWSKI, P., CZOSNYKA, M., JALLO, G. I. \& GUERGUERIAN, A. M. 2009. Continuous monitoring of cerebrovascular pressure reactivity after traumatic brain injury in children. Pediatrics, 124, e1205-12.

DAGAL, A. \& LAM, A. M. 2009. Cerebral autoregulation and anesthesia. Curr Opin Anaesthesiol, 22, 547-52.

DAWSON, S. L., PANERAI, R. B. \& POTTER, J. F. 1999. Critical closing pressure explains cerebral hemodynamics during the Valsalva maneuver. J Appl Physiol (1985), 86, 675-80.

DEWEY, R. C., PIEPER, H. P. \& HUNT, W. E. 1974. Experimental cerebral hemodynamics. Vasomotor tone, critical closing pressure, and vascular bed resistance. J Neurosurg, 41, 597-606.

DIEHL, R. R., LINDEN, D., LUCKE, D. \& BERLIT, P. 1995. Phase relationship between cerebral blood flow velocity and blood pressure. A clinical test of autoregulation. Stroke, 26, 1801-4.

EAMES, P. J., POTTER, J. F. \& PANERAI, R. B. 2005. Assessment of cerebral autoregulation from ectopic heartbeats. Clin Sci (Lond), 109, 109-15.

EVANS, D. H., LEVENE, M. I., SHORTLAND, D. B. \& ARCHER, L. N. 1988. Resistance index, blood flow velocity, and resistance-area product in the cerebral arteries of very low birth weight infants during the first week of life. Ultrasound Med Biol, 14, 103-10.

FAN, L., BUSH, G., KATSOGRIDAKIS, E., SIMPSON, D. M., ALLEN, R., POTTER, J., BIRCH, A. A. \& PANERAI, R. B. 2013. Adaptive feedback analysis and control of programmable stimuli for assessment of cerebrovascular function. Med Biol Eng Comput, 51, 709-18.

GARNHAM, J., PANERAI, R. B., NAYLOR, A. R. \& EVANS, D. H. 1999. Cerebrovascular response to dynamic changes in pCO2. Cerebrovasc Dis, 9, 146-51.

GREENE, S. A. 2010. Anesthesia for patients with neurologic disease. Top Companion Anim Med, 25, 83-6.

GUENDLING, K., SMIELEWSKI, P., CZOSNYKA, M., LEWIS, P., NORTJE, J., TIMOFEEV, I., HUTCHINSON, P. J. \& PICKARD, J, D. 2006. Use of ICM+ software for on-line analysis of intracranial and arterial pressures in head-injured patients. Acta Neurochir Suppl, 96, 108-13.

JOSHI, B., BRADY, K., LEE, J., EASLEY, B., PANIGRAHI, R., SMIELEWSKI, P., CZOSNYKA, M. \& HOGUE, C. W., JR. 2010. Impaired autoregulation of cerebral blood flow during rewarming from hypothermic cardiopulmonary bypass and its potential association with stroke. Anesth Analg, 110, 321-8.

KATSOGRIDAKIS, E., BUSH, G., FAN, L., BIRCH, A. A., SIMPSON, D. M., ALLEN, R., POTTER, J. F. \& PANERAI, R. B. 2012. Random perturbations of arterial blood pressure for the assessment of dynamic cerebral autoregulation. Physiol Meas, 33, 103-16.

KATSOGRIDAKIS, E., BUSH, G., FAN, L., BIRCH, A. A., SIMPSON, D. M., ALLEN, R., POTTER, J. F. \& PANERAI, R. B. 2013. Detection of impaired cerebral autoregulation improves by increasing arterial blood pressure variability. J Cereb Blood Flow Metab, 33, 519-23.

KATSOGRIDAKIS, E., SIMPSON, D. M., BUSH, G., FAN, L., BIRCH, A. A., ALLEN, R., POTTER, J. F. \& PANERAI, R. B. 2016. Revisiting the frequency domain: the multiple and partial coherence of cerebral blood flow velocity in the assessment of dynamic cerebral autoregulation. Physiol Meas, 37, 1056-73. 
LANG, E. W., YIP, K., GRIFFITH, J., LAGOPOULOS, J., MUDALIAR, Y. \& DORSCH, N. W. 2003. Hemispheric asymmetry and temporal profiles of cerebral pressure autoregulation in head injury. J Clin Neurosci, 10, 670-3.

LASSEN, N. A. 1959. Cerebral blood flow and oxygen consumption in man. Physiol Rev, 39, 183-238.

MICHEL, E., HILLEBRAND, S., VONTWICKEL, J., ZERNIKOW, B. \& JORCH, G. 1997. Frequency dependence of cerebrovascular impedance in preterm neonates: a different view on critical closing pressure. J Cereb Blood Flow Metab, 17, 1127-31.

NEWELL, D. W., AASLID, R., LAM, A., MAYBERG, T. S. \& WINN, H. R. 1994. Comparison of flow and velocity during dynamic autoregulation testing in humans. Stroke, 25, 793-7.

PANERAI, R. B. 2003. The critical closing pressure of the cerebral circulation. Med Eng Phys, 25, 621 32.

PANERAI, R. B., DEVERSON, S. T., MAHONY, P., HAYES, P. \& EVANS, D. H. 1999. Effects of CO2 on dynamic cerebral autoregulation measurement. Physiol Meas, 20, 265-75.

PANERAI, R. B., KELSALL, A. W., RENNIE, J. M. \& EVANS, D. H. 1995. Cerebral autoregulation dynamics in premature newborns. Stroke, 26, 74-80.

PANERAI, R. B., MOODY, M., EAMES, P. J. \& POTTER, J. F. 2005. Dynamic cerebral autoregulation during brain activation paradigms. Am J Physiol Heart Circ Physiol, 289, H1202-8.

PANERAI, R. B., SAMMONS, E. L., SMITH, S. M., RATHBONE, W. E., BENTLEY, S., POTTER, J. F., EVANS, D. H. \& SAMANI, N. J. 2006. Cerebral critical closing pressure estimation from Finapres and arterial blood pressure measurements in the aorta. Physiol Meas, 27, 1387-402.

PANERAI, R. B., WHITE, R. P., MARKUS, H. S. \& EVANS, D. H. 1998. Grading of cerebral dynamic autoregulation from spontaneous fluctuations in arterial blood pressure. Stroke, 29, 2341-6.

RASULO, F. A., DE PERI, E. \& LAVINIO, A. 2008. Transcranial Doppler ultrasonography in intensive care. Eur J Anaesthesiol Suppl, 42, 167-73.

REINHARD, M., HETZEL, A., HINKOV, V. \& LUCKING, C. H. 2000. Cerebral haemodynamics during the Mueller manoeuvre in humans. Clin Physiol, 20, 292-303.

SCHMIDT, E. A., CZOSNYKA, M., SMIELEWSKI, P., PIECHNIK,S. K. \& PICKARD, J. D. 2002. Asymmetry of cerebral autoregulation following head injury. Acta Neurochir Suppl, 81, 133-4.

SCHMIDT, E. A., CZOSNYKA, M., STEINER, L. A., BALESTRERI, M., SMIELEWSKI, P., PIECHNIK, S. K., MATTA, B. F. \& PICKARD, J. D. 2003a. Asymmetry of pressure autoregulation after traumatic brain injury. J Neurosurg, 99, 991-8.

SCHMIDT, E. A., PIECHNIK, S. K., SMIELEWSKI, P., RAABE, A., MATTA, B. F. \& CZOSNYKA, M. 2003b. Symmetry of cerebral hemodynamic indices derived from bilateral transcranial Doppler. $J$ Neuroimaging, 13, 248-54.

SERRADOR, J. M., PICOT, P. A., RUTT, B. K., SHOEMAKER, J. K. \& BONDAR, R. L. 2000. MRI measures of middle cerebral artery diameter in conscious humans during simulated orthostasis. Stroke, 31, 1672-8.

SHARMA, D., BITHAL, P. K., DASH, H. H., CHOUHAN, R. S., SOOKPLUNG, P. \& VAVILALA, M. S. 2010. Cerebral autoregulation and $\mathrm{CO} 2$ reactivity before and after elective supratentorial tumor resection. J Neurosurg Anesthesiol, 22, 132-7.

VAVILALA, M. S., TONTISIRIN, N., UDOMPHORN, Y., ARMSTEAD, W., ZIMMERMAN, J. J., CHESNUT, R. \& LAM, A. M. 2008. Hemispheric differences in cerebral autoregulation in children with moderate and severe traumatic brain injury. Neurocrit Care, 9, 45-54.

WEYLAND, A., BUHRE, W., GRUND, S., LUDWIG, H., KAZMAIER, S., WEYLAND, W. \& SONNTAG, H. 2000. Cerebrovascular tone rather than intracranial pressure determines the effective downstream pressure of the cerebral circulation in the absence of intracranial hypertension. J Neurosurg Anesthesiol, 12, 210-6.

ZHANG, R., ZUCKERMAN, J. H. \& LEVINE, B. D. 1998. Deterioration of cerebral autoregulation during orthostatic stress: insights from the frequency domain. J Appl Physiol (1985), 85, 1113-22. 

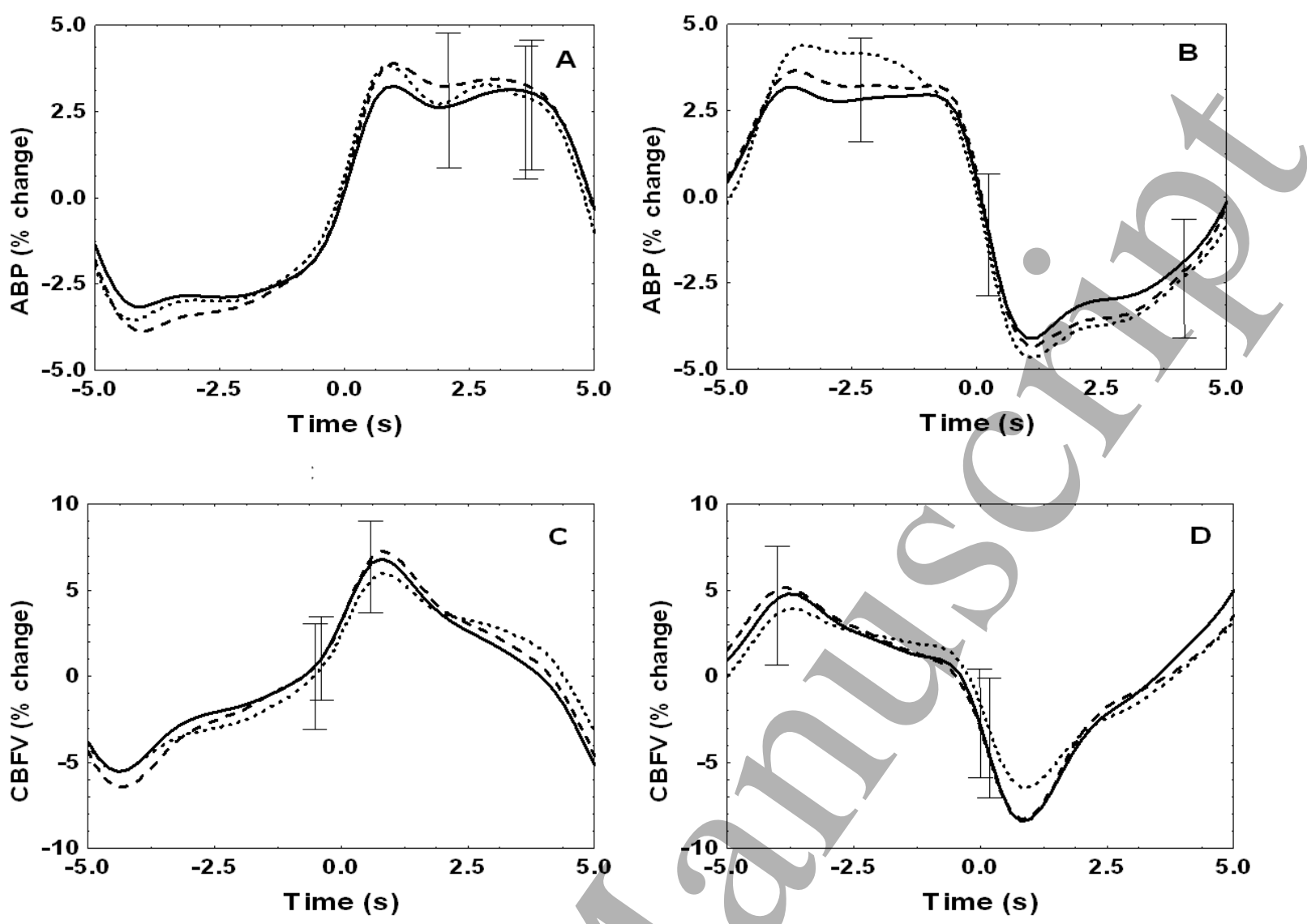

Figure 1. Population estimates of the ABP (subplot/A) and CBFV (subplot C) coherent averages in response to thigh cuff inflation, along with population estimates of the ABP (subplot B) and CBFV (subplot D) coherent averages in response to thigh cuff deflation. The solid line represents estimates obtained for manoeuvres undertaken in normocapnic conditions, the dashed line for intermittent / pseudorandom hypercapnic conditions and the dotted line for constant hypercapnic conditions. Error bars represent the largest \pm 1 SEM. 

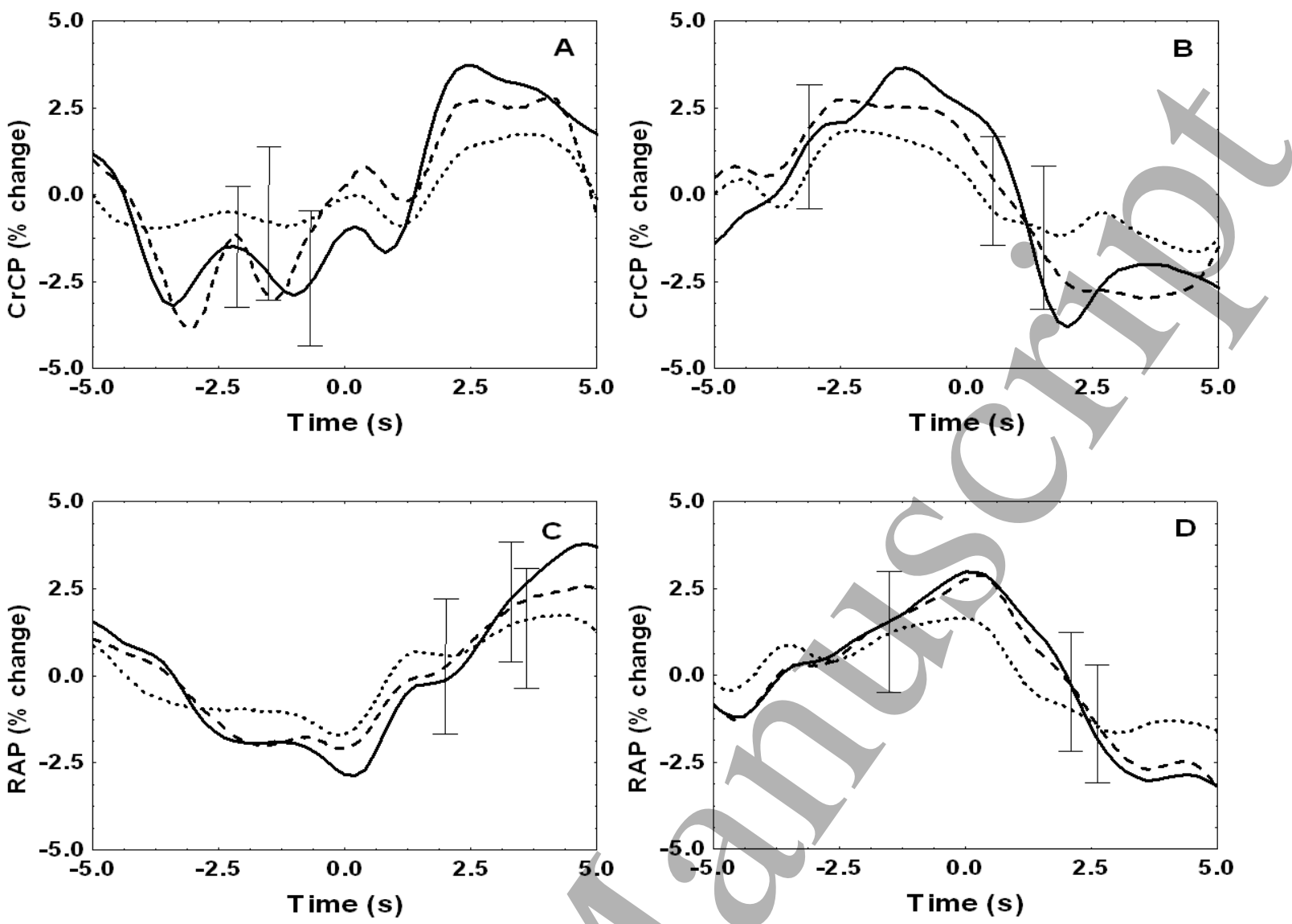

Figure 2. Population estimates of the $\mathrm{CrCP}$ (subplot A) and RAP (subplot C) coherent averages in response to thigh cuff inflation, along with population estimates of the $\mathrm{CrCP}$ (subplot B) and RAP (subplot D) coherent averages in response to thigh cuff deflation. The solid line represents estimates obtained for manoeuvres undertaken in normocapnic conditions, the dashed line for intermittent / pseudorandom hypercapnic conditions and the dotted line for constant hypercapnic conditions. Error bars represent the largest \pm 1 SEM. 

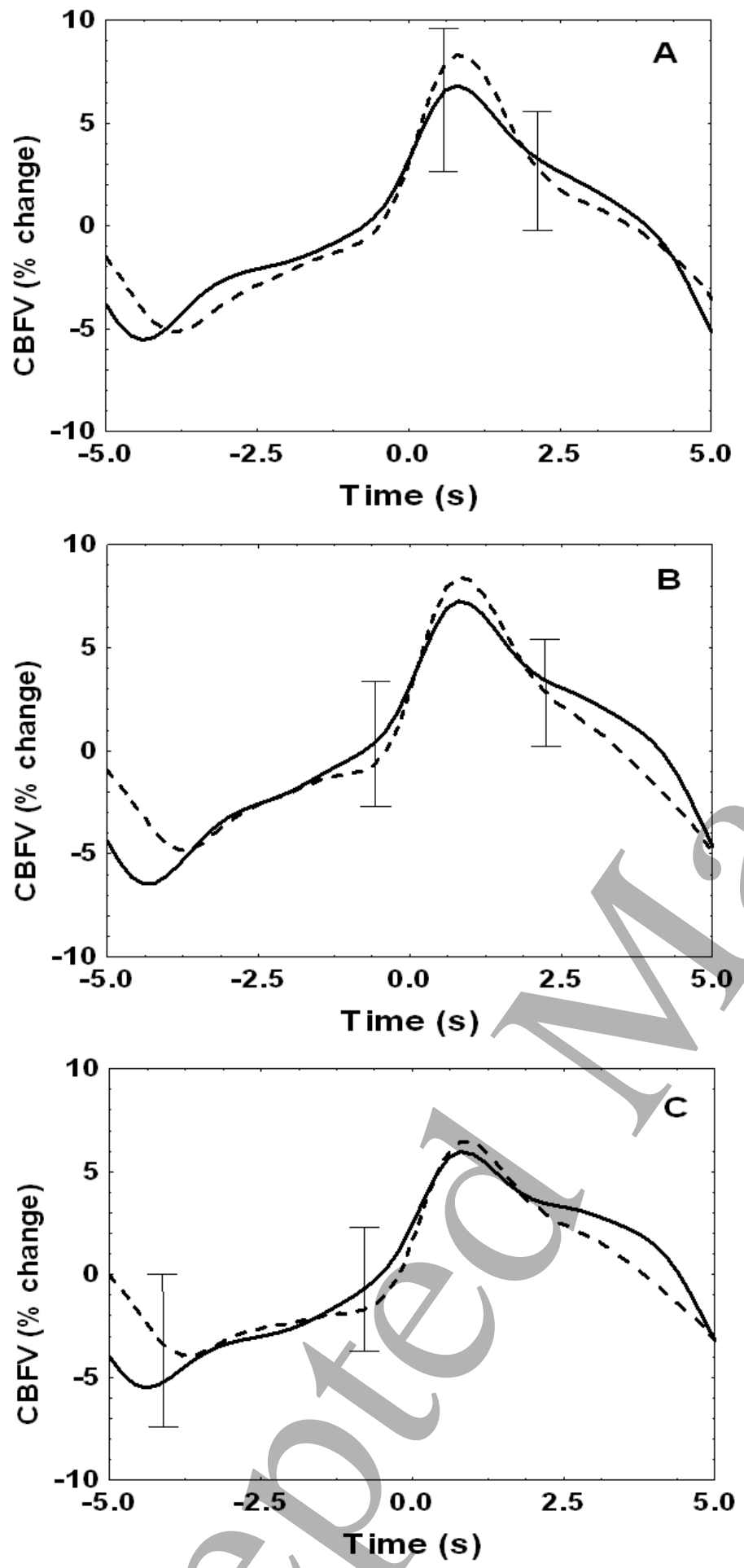

Figure 3. Population estimates for the averaged and inverted CBFV responses under normocapnic (A), intermittent hypercapnic (B) and constant hypercapnic conditions (C). Solid line: CBFV response, dashed line: inverted CBFV response. Error bars represent the largest \pm 1 SEM. 
Table 1: Slope coefficients for the linear regression between ABP \& CBFV, ABP \& CrCP and ABP \& RAP

\section{Direction}

\section{Parameter}

$C B F V$

Normocapnia

Intermittent Hypercapnia

Constant Hypercapnia

$\operatorname{CrCP}$

Normocapnia

Intermittent Hypercapnia

Constant Hypercapnia

$R A P$

Normocapnia

Intermittent Hypercapnia

Constant Hypercapnia
Up

Down

p-values

$0.50 \pm 0.320 .48 \pm 0.35 \quad \mathrm{p}=0.002\left(\right.$ effect of $\left.\mathrm{CO}_{2}\right)$

$0.57 \pm 0.33 \quad 0.58 \pm 0.31 \quad \mathrm{p}=0.369$ (effect of direction)

$0.71 \pm 0.45 \quad 0.69 \pm 0.42$

$$
\begin{array}{ccc}
0.85 \pm 0.31 & 0.90 \pm 0.30 & \mathrm{p}<10^{-4} \quad\left(\text { (effect of } \mathrm{CO}_{2}\right) \\
0.38 \pm 0.34 & 0.41 \pm 0.34 & \mathrm{p}=0.105 \text { (effect of direction) } \\
-0.12 \pm 0.39 & -0.09 \pm 0.39 & \mathrm{p}=0.135 \text { (effect of interaction) }
\end{array}
$$

$$
\begin{aligned}
& 0.003 \pm 0.0080 .003 \pm 0.008 p<10^{-4} \quad\left(\text { effect of } \mathrm{CO}_{2}\right) \\
& 0.005 \pm 0.0060 .006 \pm 0.010 \mathrm{p}=0.481 \text { (effect of direction) } \\
& 0.010 \pm 0.0140 .016 \pm 0.013 \mathrm{p}=0.643 \text { (effect of interaction) }
\end{aligned}
$$

